\section{An unusual case of chest pain: ultrasonographic diagnosis of Mondor's disease}

\section{Bahjat Barakat, ${ }^{1}$ Raffaele Pezzilli ${ }^{2}$ ${ }^{1}$ Department of Emergency Medicine, S. Orsola-Malpighi Hospital; ${ }^{2}$ Department of Digestive Diseases and Internal Medicine, S. Orsola-Malpighi Hospital, Bologna, Italy}

\section{Abstract}

Mondor's disease is characterized by superficial thrombophlebitis affecting the subcutaneous veins, especially those of the anterolateral thoracoabdominal wall. Thrombophlebitis is usually a subcutaneous, tender, painful cordlike induration, usually found in the breast or the axilla. It typically affects middle-aged women. Thus, we believe the case of a 48-yearold male patient admitted to the emergency room for chest pain with a palpable, non-erythematous, and painful cord-like structure localized in the anterior chest wall and the abdomen to be of interest. He had had a mild thoracic trauma. Doppler analysis showed a thrombosis of the superficial vein of the thorax. The patient was treated by Fondaparinux Sodium $2.5 \mathrm{mg}$ subcutaneously per day for 30 days. Evolution was favorable. Although uncommon, Mondor's disease has to be recognized to avoid useless diagnosis testing and to deliver a specific treatment.

\section{Introduction}

Mondor's disease is a unusual form of superficial thrombophlebitis affecting the subcutaneous veins, particularly those of the anterolateral thoracoabdominal wall. Even if the first report was that of Faage in $1869,{ }^{1}$ it was characterized by Henri Mondor, a French surgeon in 1939. ${ }^{2}$ Although Mondor's disease is rare, it is believed to be more common than reported. ${ }^{3}$ Patients sometimes do not seek medical care because it is a benign and selflimiting disease. Thus, we believe the case of a male patient admitted to the emergency room (ER) for chest pain and diagnosed as having Mondor's disease to be of interest.

\section{Case Report}

A 48-year-old male patient was admitted to ER for chest pain with a palpable, non-erythematous and painful cord-like structure extend- ing from the right side of the anterolateral chest wall to the right iliac fossa (Figure 1); this lesion appeared about five days after a mild trauma of the thorax while the patient was at work. The past medical history was unremarkable apart from an appendectomy at the age of 12 years. He was not a drug addict and was not on any medication. He had no fever, the arterial pressure was normal as were both the cardiac and the respiratory rates. Physical examination of the abdomen was normal as were the respiratory, cardiac and neurological examinations. There was no clubbing, cyanosis or edema of the extremities. An electrocardiogram showed no alterations. Biochemical examinations were normal and no alterations of coagulation tests were detected; there was also no deficiency of protein $\mathrm{S}$, protein $\mathrm{C}$ or antithrombin III, nor the presence of anticardiolipin antibodies. A chest X-ray was carried out showing no alteration of the lungs, the absence of pleural fluid collections and a normal cardiac silhouette. Ultrasonography showed a hypoechoic tubular structure with a thrombus occluding the vessel examined; this picture was compatible with superficial thrombophlebitis (Figure 2). These findings were confirmed at Doppler analysis, showing the absence of a flow in this abnormal tubular structure (Figure 3) which showed thrombosis of the superficial vein of the chest wall. The patient was treated with fondaparinux sodium at a dosage of $2.5 \mathrm{mg}$ per day subcutaneously for 30 days and with nonsteroidal antiinflammatory drugs (NSAIDs). The results were favorable and the lesion disappeared rapidly as did the chest pain, which was also demonstrated by ultrasonographic examination (Figure 4).

\section{Discussion}

The etiology of Mondor's disease is still unknown. Several predisposing factors have been described, such as vessel-wall damage, stasis and a hypercoagulable state. ${ }^{4}$ The etiology is usually related to a trauma as in our patient, surgery, ${ }^{5}$ muscular strain ${ }^{6}$ or electrocution. ${ }^{7}$ It may also be due to bacterial and viral infections. ${ }^{8}$ Mondor's disease has been found to be associated with primary or metastatic mammary carcinoma, especially in women. ${ }^{4,5}$ The localization of Mondor's disease in men has also been reported outside the chest and has also been associated with the absence of a dorsal penile artery together with erectile dysfunction, ${ }^{9}$ following intensive and vigorous sexual activity ${ }^{10}$ and traumatic funicular phlebitis. ${ }^{11}$

From a pathological point of view, the disorder develops at different stages; initially, a dense inflammatory cell infiltrate, a thrombus then develops occluding the lumen of the affected veins, and connective tissue prolifera-
Correspondence: Raffaele Pezzilli, Department of Digestive Diseases and Internal Medicine, S. Orsola-Malpighi Hospital, via Pietro Albertoni 15, 40138 Bologna, Italy.

Tel. +39.051.6364148 - Fax: +39.051.6364148.

E-mail: raffaele.pezzilli@aosp.bo.it

Key words: Mondor's disease, ultrasonography, doppler examination, thromboplebitis, therapeutics.

Contributions: the authors contributed equally.

Conflict of interests: the authors declare no potential conflict of interests.

Received for publication: 15 February 2013. Accepted for publication: 11 April 2013.

This work is licensed under a Creative Commons Attribution 3.0 License (by-nc 3.0).

(C) Copyright B. Barakat and R. Pezzilli, 2013

Licensee PAGEPress, Italy

Emergency Care Journal 2013; 9:e5

doi:10.4081/ecj.2013.e5

tion takes place in the vessel with the formation of a hard cord. Finally, the disease resolves with the recanalization of the vein. ${ }^{12}$

Diagnostic tests must be carried out when Mondor's disease is suspected. The differential diagnosis includes subacute angeitis, cutaneous polyarteritis nodosa and angeitis due to drugs $;^{3}$ however, these disorders are usually more painful, and inflammatory conditions affect the arteries rather than the veins. Our patient was not a drug addict and was not on any medication, thus, we hypothesized Mondor's disease.

Coagulation tests must be carried out in order to exclude hypercoagulability conditions, such as a deficiency of protein $\mathrm{S}$, protein $\mathrm{C}$ or antithrombin III, or the presence of anticardiolipin antibodies $;^{13}$ in fact, in the case herein reported, no alteration of coagulation was found.

Ultrasonography is useful in confirming Mondor's disease and excluding the existence of any underlying mass compressing the veins. As in our case, sonography usually reveals a distended flowless vein tending to be longer than a duct and having a beaded appearance, usually located in the upper external quadrant of the breast; in acute cases, a thrombus may occasionally be present as was found in this

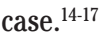

Several treatment options have been proposed. Most patients require only symptomatic treatment; anti-inflammatory drugs combined with anticoagulant therapy may decrease the healing time. In cases with intense and persistent pain, the use of anesthetic infiltrations around the lesion has been suggested. ${ }^{4,14}$ 


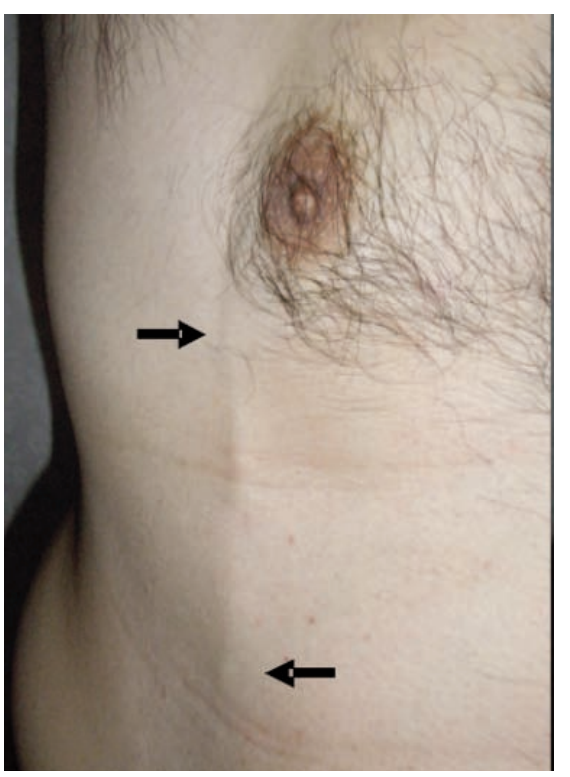

Figure 1. Palpable, non-erythematous and painful cord-like structure, extending from the right side of the anterior chest wall (upper arrow) to the right iliac fossa (lower arrow).

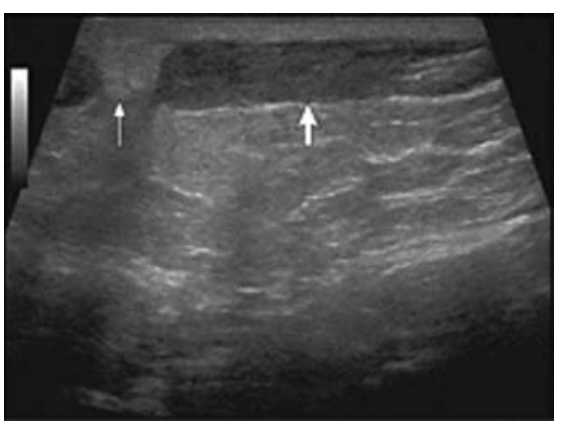

Figure 2. Ultrasonography examination showing a thrombus within the vessel (indicated by arrows).

When this treatment is not sufficient for healing or when the disease recurs, a thrombectomy or superficial vein resection is carried out. ${ }^{6}$ Mondor's disease is not usually a risk factor for recurrent thrombophlebitis; this event is very rare and can be found in about $3 \%$ of cases. However, superficial thrombophlebitis has been reported in association with deep-vein thrombosis. The association with other thrombotic events such as pulmonary embolism, coronary syndromes or stroke, are also very uncommon events in a rare illness such as Mondor's disease. ${ }^{3}$ It is important to keep in mind that Mondor's disease can present as isolated phlebitis or as part of a generalized superficial thrombophlebitis. ${ }^{18}$

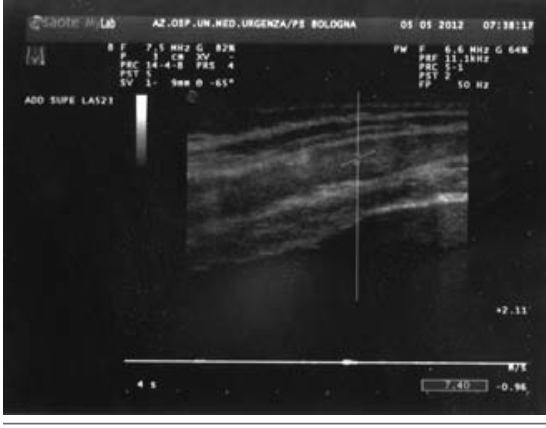

Figure 3. Doppler analysis showing the absence of flow in this abnormal tubular structure.

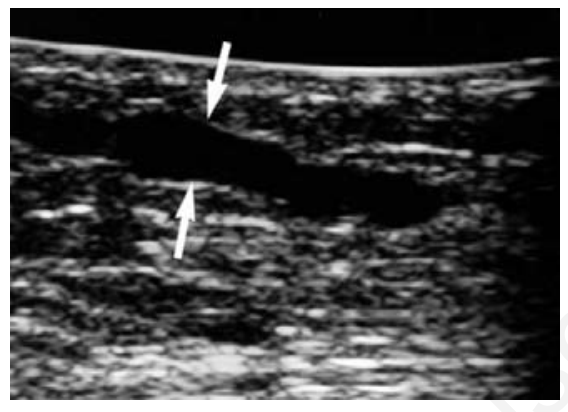

Figure 4. Ultrasonography examination showing the complete healing of the thrombophlebitis (indicated by arrows).

\section{Conclusions}

In conclusion, we should be aware of this condition not only in females but also in male patients having persistent chest pain; diagnosis can be achieved by a simple physical examination which can easily be confirmed by external ultrasonography.

\section{References}

1. Fagge CH. Remarks on certain cutaneous affections. Guys Hosp Rep 1869;15:295302.

2. Mondor H. [Tronculite sous-cutanée subaigue de la paroi thoracique anterol-laterale]. [Article in French]. Mem Acad Chir (Paris) 1939;65:1271-8.

3. Alvarez-Garrido H, Garrido-Ríos AA, SanzMuñoz C, Miranda-Romero A. Mondor's disease. Clin Exp Dermatol 2009;34:753-6.

4. Mayor M, Burón I, de Mora JC, et al.
Mondor's disease. Int J Dermatol 2000;39: 922-5.

5. Pappo I, Wasserman I, Stahl-Kent V, et al. Mondor's disease of the axilla: a rare complication of sentinel node biopsy. Breast $\mathrm{J}$ 2004;10:253-5.

6. Onder M, Canpolat B, Aksakal B, Gurer MA. Case of Mondor's disease of the abdomen (body-building induced). Int $\mathrm{J}$ Dermatol 2005;44:345-6.

7. Randell P. Mondor's disease and electrocution. Australas J Dermatol 2003;44:75-6.

8. Yang J, Lee U, Jang S, Choi JC. Mondor's disease probably due to herpes zoster. J Eur Acad Dermatol 2005;19:774-5.

9. Ozel A, Issayev F, Erturk SM, et al. Sonographic diagnosis of penile Mondor's disease associated with absence of a dorsal penile artery. J Clin Ultrasound 2010; 38: 263-6.

10. Rowe M, Depraetere K. A presentation of penile Mondor's disease. Int J STD AIDS 2012;23:681-2.

11. Kondo T. Traumatic funicular phlebitis of the thoracic wall resembling Mondor's disease: a case report. J Med Case Rep 2011; 5:127.

12. Ichinose A, Fukunaga A, Terashi $\mathrm{H}$, et al. Objective recognition of vascular lesions in Mondor's disease by immunohistochemistry. J Eur Acad Dermatol 2008;22: 168-73.

13. Boehlen F, Bader M, Moerloose P. Superficial thrombophlebitis of the chest wall associated with anticardiolipin antibodies: antiphospholipid syndrome or Mondor's disease? Lupus 2004;13:70-1.

14. Shetty MK, Waton AB. Mondor's disease of the breast: sonographic and mammographic findings. Am J Roentgenol 2001; 177:893-6.

15. Thatipelli MR, Hand DL, Irwin WT, et al. Images in vascular medicine. A variant of Mondor's disease. Vasc Med 2007;12:1356.

16. Yanik B, Conkbayir I, Oner 0, Hekimoğlu B. Imaging findings in Mondor's disease. J Clin Ultrasound 2003;31:103-7.

17. Barnes R, Wu K, Hoak J. Differentiation of superficial thrombophlebitis from lymphangitis by Doppler ultrasound. Surg Gynecol Obstet 1976;143:23-5.

18. Rodriguez-Peralto JL, Carrillo R, Rosales B, Rodríguez-Gil Y. Superficial thrombophlebitis. Semin Cutan Med Surg 2007; 26:71-6. 